\title{
Studies on the Growth and Characterization of L-Arginine Maleate Dihydrate Crystal Grown from Liquild Diffusion Technique
}

\author{
K. Ramya ${ }^{1 *}$, C. Ramachandra Raja ${ }^{2}$ \\ ${ }^{1}$ Department of Physics, TUK Arts College, Thanjavur, India \\ ${ }^{2}$ Department of Physics, Government Arts College (Autonomous), Kumbakonam, India \\ Email: 'ramya1058@gmail.com
}

Received 6 February 2016; accepted 27 March 2016; published 30 March 2016

Copyright (C) 2016 by authors and Scientific Research Publishing Inc.

This work is licensed under the Creative Commons Attribution International License (CC BY). http://creativecommons.org/licenses/by/4.0/

c) (i) Open Access

\begin{abstract}
Nonlinear optical crystals of L-Arginine maleate dihydrate were grown from liquid diffusion method. The lattice parameters of the crystal were identified using single crystal and powder crystal $\mathrm{X}$-ray diffraction analyses. Fourier transform infrared spectroscopy and Fourier transform Raman spectroscopy were made to study the vibrational functional groups in the grown crystal. Optical absorption and transmission ranges were measured from UV-VIS-NIR spectrum. The molecular structure of the crystal is established through ${ }^{1} \mathrm{H}$-NMR and ${ }^{13} \mathrm{C}$-NMR studies. Thermal stabilities and decomposition of the grown crystal were studied from TG/DTA and DSC analyses. Nonlinear optical property of the crystal was determined by Kurtz and Perry powder technique.
\end{abstract}

\section{Keywords}

\section{Amino Acids, Liquid Diffusion Method, NMR Spectral Studies, Nonlinear Optical Material}

\section{Introduction}

Organic nonlinear optical materials are of great interest due to its demand in optical communication technologies. These materials have good mechanical and chemical stability, and sufficiently much larger number of design possibilities, which are used in optical information processing, optical disk storage, optical computing and telecommunications [1]. A large number of organic nonlinear optical materials have been accounted because of its nonlinear optical and photonics applications. Amino acid mixed organic crystals have great attention in the optical applications compared to other materials [2]. The conjugated pi molecules containing an electron accep-

*Corresponding author.

How to cite this paper: Ramya, K. and Raja, C.R. (2016) Studies on the Growth and Characterization of L-Arginine Maleate Dihydrate Crystal Grown from Liquid Diffusion Technique. Journal of Minerals and Materials Characterization and Engineering, 4, 143-153. http://dx.doi.org/10.4236/jmmce.2016.42014 
tor and donor groups provide a large degree of second order optical nonlinearity [3] [4]. The acceptor and donor groups with large transition dipole moments and large difference in energy between ground and excited states exhibit large second order optical nonlinearity of the molecules. The basic amino acid L-Arginine gains more interest in the development of nonlinear optical materials and the maleic acid-a basic dicarboxylic acid has great attention due to its large pi conjugation [5]. The growth of the crystal, L-Arginine maleate dihydrate and its characterization is already reported [6]-[12]. In all these works, the growth is carried out using low temperature solution growth technique. In this paper, L-Arginine maleate dihydrate is grown from liquid diffusion method and the grown crystals were characterized by Single and Powder crystal X-Ray Diffraction analyses (XRD), Fourier Transform Infra Red Spectroscopy (FTIR), Fourier Transform Raman Spectroscopy (FT Ramam), Nuclear Magnetic Resonance Spectroscopy (NMR), Thermal studies, optical characterization like UV-VIS-NIR Spectroscopy, and Second Harmonic Generation (SHG) property.

Basically, some salts of amino acid with different organic or inorganic acids can be grown from the standard method of synthesizing the aqueous solution of the required materials mixed in a molar proportion, and purifying the solution and then evaporating the solvent by slow evaporation technique. But in some cases, this method does not lead to the expected product, in which no reaction takes place between the starting materials, and the resulting crystal formation is simply any one of the starting materials. The liquid diffusion technique is employed to overcome such difficulties. In this technique, two solvents are chosen. One solvent is allowed to diffuse into the other solvent. An aqueous solution of the compound is prepared and chosen as the first solvent. A less dense solvent, in which the compound is insoluble, is chosen as the second solvent. Two solvents are added so that they form a distinct layer, where the lower dense solvent adds diffuses slowly as the precipitant in to an aqueous solution of the compound with the formation of crystals at the liquid boundary.

\section{Experimental}

\subsection{Materials and Methods}

Crystals of L-Arginine maleate dihydrate were obtained from liquid diffusion method. Aqueous solution of the amino acid L-Arginine and the maleic acid was prepared in an equimolar proportion. The solvent acetonitrile is added to the prepared compound, since the compound is insoluble in the solvent. Crystals of L-Arginine maleate dihydrate were grown when the solvent acetonitrile, diffuses slowly as the precipitant into an aqueous solution of L-Arginine and maleic acid. Transparent crystals of L-Arginine maleate dihydrate were grown in a period of one week. The formation of crystal follows the reaction.

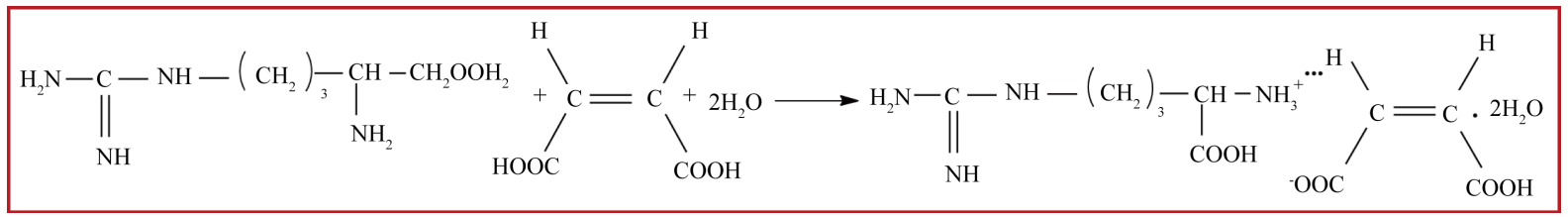

L-Arginine

Maleic acid

L-Arginine maleate dihydrate

\subsection{Characterization}

The grown L-Arginine maleate dihydrate crystal was subjected to various characterization techniques like single and powder crystal X-ray diffraction, Fourier transform infrared and Fourier transform Raman spectral studies, UV-VIS spectral analysis, Nuclear magnetic resonance spectral analyses, thermal analysis and nonlinear optical studies. Nonius CAD4/MACH 3 single crystal X-Ray diffractometer with $\operatorname{MoK} \alpha(\lambda=0.71069 \AA)$ radiation and D8 phaser Bruker powder diffractometer were used to find the lattice parameter values. Fourier Transform Infra Red spectrum was recorded by the KBr pellet technique using a SPECTROMRX1 FTIR spectrometer and BRUKER RFS 27 spectrometer records the FT Raman spectrum to confirm the functional groups. The optical absorption and transmission spectra were recorded in the region $190 \mathrm{~nm}$ to $1100 \mathrm{~nm}$ using $\lambda 35$ model PerkinElmer double beam UV-VIS-NIR spectrometer. The instrument Bruker $300 \mathrm{MHz}$ (ultrasheild) ${ }^{\mathrm{TM}}$ at room temperature $\left({ }^{1} \mathrm{H}-\mathrm{NMR}\right.$ at $300 \mathrm{MHz},{ }^{13} \mathrm{C}$-NMR at $\left.75 \mathrm{MHz}\right)$ records the ${ }^{1} \mathrm{H}-\mathrm{NMR}$ and ${ }^{13} \mathrm{C}-\mathrm{NMR}$ spectra by dissolving the crystal in $\left(\mathrm{D}_{2} \mathrm{O}\right)$ heavy water for the confirmation of molecular structure. The thermal characterization was determined from SDT Q600 V20.9 Build 20 instrument in a nitrogen atmosphere in temperature range $30^{\circ} \mathrm{C}$ - 
$1100^{\circ} \mathrm{C}$. Kurtz Perry powder technique was used to measure the second harmonic generation efficiency. Nd:YAG Q-switched mode locked laser with a harmonic output at $1064 \mathrm{~nm}$, and an input energy of $1.6 \mathrm{~mJ} /$ pulse with a pulse width of $10 \mathrm{~ns}$ at a repetition rate of $10 \mathrm{~Hz}$ was used for the measurement of an efficiency of second harmonic generation.

\section{Results and Discussion}

\subsection{Single Crystal and Powder XRD Studies}

Single crystal X-ray diffraction analysis was carried out to find the lattice parameters. This study reveals that the grown crystal of L-Arginine maleate dihydrate belongs to the Triclinic system with P1 space group. The determined lattice parameters are listed in Table 1.

The crystallinity and structure of the L-Arginine maleate dihydrate crystal have been confirmed by powder diffraction analysis. The crushed powder sample was subjected to intense X-rays of wavelength $1.5418 \AA$ $\left(\mathrm{CuK}_{\alpha}\right)$ at a scan speed of $1 \%$ minute. The observed powder XRD pattern in Figure 1 has been indexed by Rietveld Index software package. The lattice parameters have been calculated by Rietveld Unit Cell software package and they are shown in Table 1. It is observed that lattice parameters of L-Arginine maleate dihydrate from single and powder crystal XRD data were in good agreement with the already reported values [7].

Table 1. Lattice parameters of L-Arginine maleate dihydrate crystal.

\begin{tabular}{cccc}
\hline Lattice parameters & $\begin{array}{c}\text { Lattice parameters from } \\
\text { single crystal data }\end{array}$ & $\begin{array}{c}\text { Lattice parameters from } \\
\text { powder crystal data }\end{array}$ & 5.3123 \\
$\mathrm{a}(\AA)$ & 5.32 & 8.1292 & 8.039 \\
$\mathrm{~b}(\AA)$ & 8.12 & 9.8857 & 9.784 \\
$\mathrm{c}(\AA)$ & 9.88 & 106.71 & 96.19 \\
$\alpha^{\circ}$ & 106.35 & 96.99 & 97.24 \\
$\beta^{\circ}$ & 97.26 & 102.24 & 101.66 \\
$\gamma^{\circ}$ & 101.86 & & 9 \\
\hline
\end{tabular}

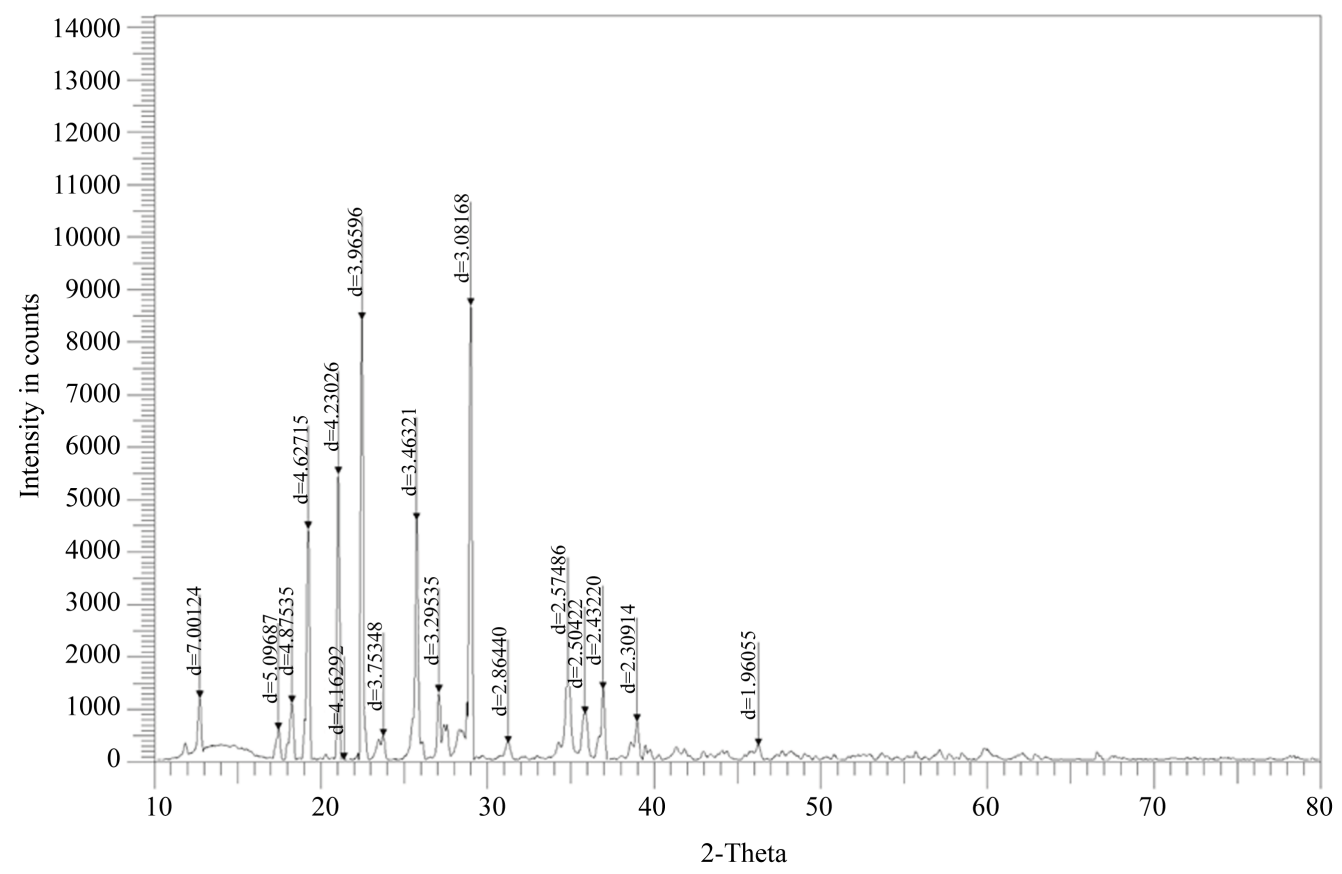

Figure 1. Powder XRD pattern of L-Arginine maleate dihydrate crystal. 


\subsection{Vibrational Spectral Analyses}

FTIR and FT Raman studies are the useful techniques for the identification of compounds. The recorded FTIR and FT Raman spectra of L-Arginine maleate dihydrate crystal are depicted in Figure 2 and Figure 3.

The IR band at $2951 \mathrm{~cm}^{-1}$ is assigned to $\mathrm{CH}_{3}$ asymmetric stretching vibration, whereas its Raman peak is located at $2925 \mathrm{~cm}^{-1}$. The peaks at $1677 \mathrm{~cm}^{-1}$ in FTIR and its Raman equivalent observed at $1680 \mathrm{~cm}^{-1}$ is due to asymmetric deformation of $\mathrm{NH}_{3}^{+}$group. The IR bands at $1627 \mathrm{~cm}^{-1}$ and $1389 \mathrm{~cm}^{-1}$ are assigned to $\mathrm{COO}^{-}$ asymmetric and symmetric stretching vibrations. Their Raman counterparts are resolved at $1610 \mathrm{~cm}^{-1}$ and 1392 $\mathrm{cm}^{-1}$ respectively. The rocking and stretching of $\mathrm{NH}_{3}^{+}$and $\mathrm{CN}$ groups both in IR and Raman occurs at 1166 $\mathrm{cm}^{-1}, 1111 \mathrm{~cm}^{-1}, 1172 \mathrm{~cm}^{-1}$ and $1109 \mathrm{~cm}^{-1}$ respectively. The bands in FTIR and Raman at $868 \mathrm{~cm}^{-1}$ and 851 $\mathrm{cm}^{-1}$ are assigned to $\mathrm{COO}^{-}$rocking vibration. The IR band at $661 \mathrm{~cm}^{-1}$ is due to the rocking of $\mathrm{CH}_{2}$ group, and its corresponding band in Raman occurs at $662 \mathrm{~cm}^{-1}$. The peak at $573 \mathrm{~cm}^{-1}$ and $545 \mathrm{~cm}^{-1}$ in IR and Raman are ascribed to $\mathrm{COO}^{-}$wagging mode of vibration. The detailed assignments based on the recorded FTIR and FT Raman spectra are presented in Table 2 and Table 3. From Table 3, most of the vibrations present in both Infrared and Raman spectra are same, thus confirming the non-centrosymmetric nature of the crystal.

\subsection{Optical Studies}

The UV-VIS-NIR absorption and transmission spectra were recorded in the range between $190 \mathrm{~nm}$ to1100 $\mathrm{nm}$. The observed spectra are shown in Figure 4 and Figure 5. From the observed spectrum, the lower cut-off wavelength is found to be $238 \mathrm{~nm}$ and there is no absorption in the visible region and near infrared region. All amino acids possess the property, that the absorption of radiation is absent in the entire visible region [13] [14]. The absence of absorption in this region provides as the source for second harmonic generation. Thus, the absorption studies reveal that the crystal L-Arginine maleate dihydrate acts as a suitable material for second harmonic generation in the visible and near infrared regions.

\subsection{NMR Studies}

The carbon-hydrogen bonded network of the crystal was analyzed by ${ }^{1} \mathrm{H}-\mathrm{NMR}$ and ${ }^{13} \mathrm{C}$-NMR spectra. The ${ }^{1} \mathrm{H}-\mathrm{NMR}$ and ${ }^{13} \mathrm{C}$-NMR spectra of L-Arginine maleate dihydrate are shown in Figure 6 and Figure 7 respectively and their chemical shifts with the assignments are tabulated in Table 4 and Table 5.

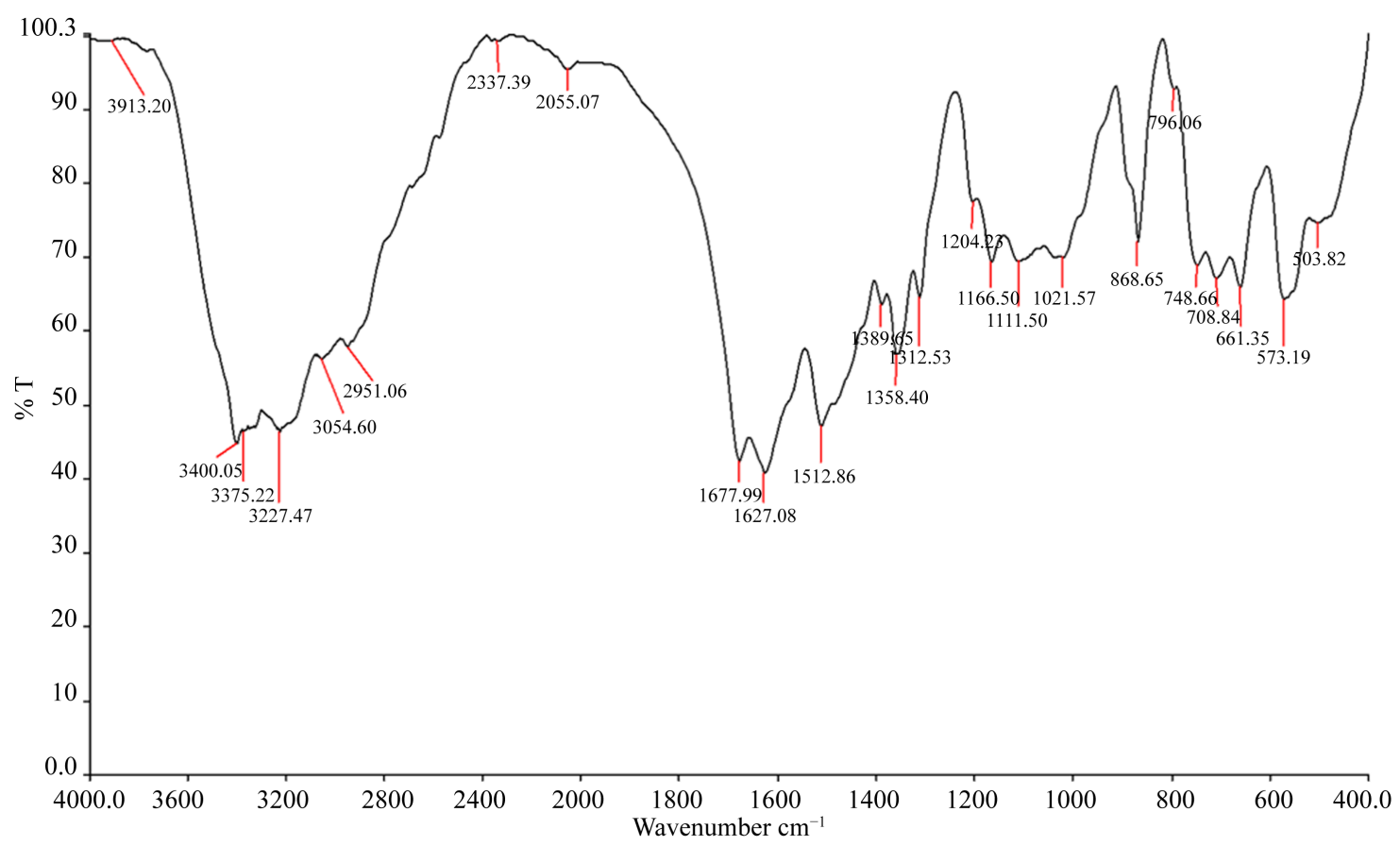

Figure 2. FTIR Spectrum of L-Arginine maleate dihydrate crystal. 


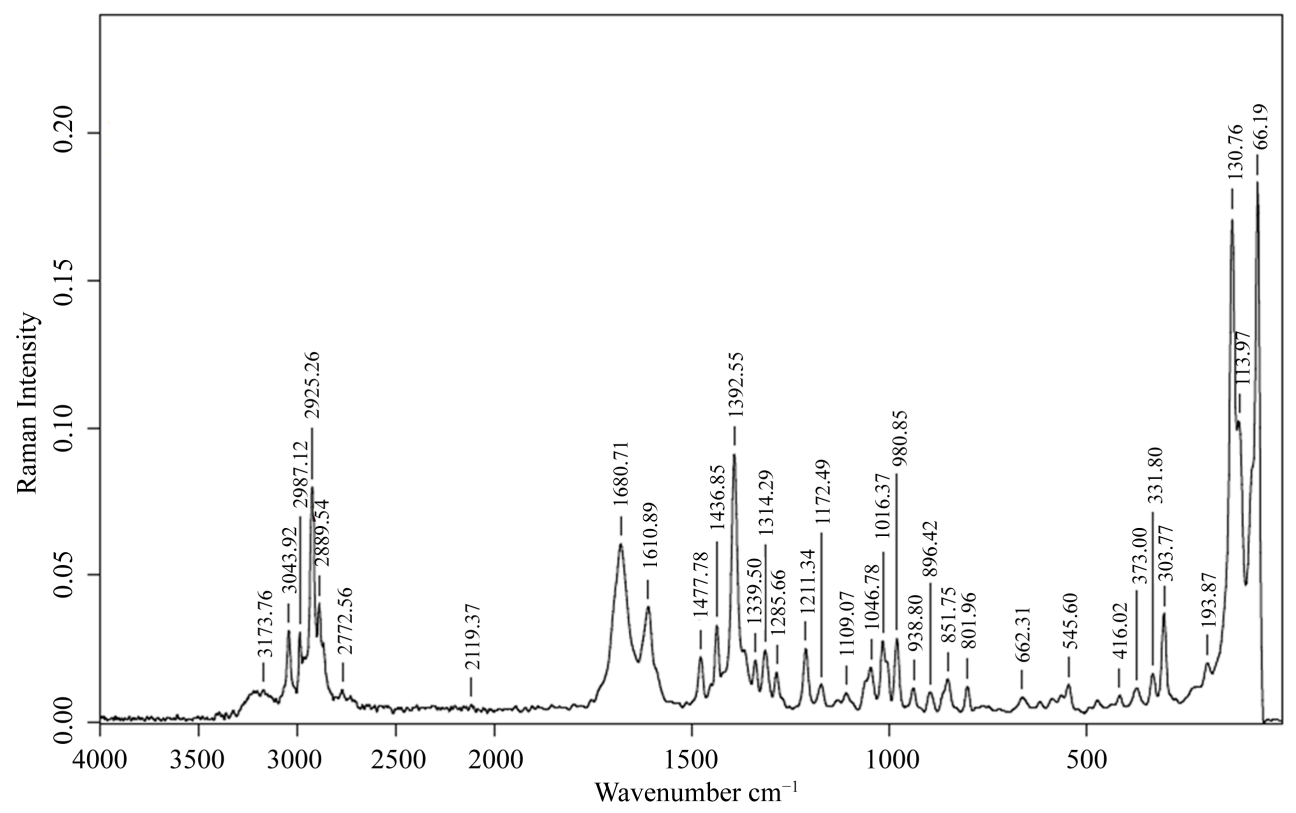

Figure 3. FT-Raman Spectrum of L-Arginine maleate dihydrate crystal.

Table 2. FTIR vibrational assignments of L-Arginine maleate dihydrate crystal.

\begin{tabular}{|c|c|c|c|}
\hline \multicolumn{3}{|c|}{ Wavelength $\left(\mathrm{cm}^{-1}\right)$} & \multirow{2}{*}{ Assignments } \\
\hline L-Arginine & Maleic acid & L-Arginine maleate dihydrate & \\
\hline 3359 & - & 3375 & $\mathrm{NH}_{2}$ asymmetric stretching \\
\hline 2925 & 2924 & 2951 & $\mathrm{CH}_{3}$ asymmetric stretching \\
\hline 1679 & - & 1677 & $\mathrm{NH}_{3}$ asymmetric deformation \\
\hline 1619 & 1637 & 1627 & $\mathrm{COO}^{-}$asymmetric stretching \\
\hline 1556 & - & 1512 & $\mathrm{NH}_{3}$ deformation \\
\hline 1377 & 1376 & 1389 & $\mathrm{COO}^{-}$symmetric stretching \\
\hline 1362 & 1367 & 1358 & $\mathrm{C}-\mathrm{CH}$ in plane deformation \\
\hline 1333 & - & 1312 & $\mathrm{CH}$ bending \\
\hline 1186 & - & 1166 & $\mathrm{NH}_{3}^{+}$rocking \\
\hline 1139 & - & 1111 & $\mathrm{CN}$ stretching \\
\hline 847 & 863 & 868 & $\mathrm{COO}^{-}$rocking \\
\hline 771 & 786 & 796 & $\mathrm{CH}$ rocking \\
\hline 713 & - & 708 & $\mathrm{NH}_{2}$ out of plane bending \\
\hline 623 & 633 & 661 & $\mathrm{CH}_{2}$ rocking \\
\hline 561 & - & 573 & $\mathrm{COO}^{-}$wagging \\
\hline 493 & 489 & 503 & COO rocking \\
\hline
\end{tabular}

The resonance peaks at $\delta=1.629 \mathrm{ppm}$ and at $\delta=1.889 \mathrm{ppm}$ in the ${ }^{1} \mathrm{H}-\mathrm{NMR}$ spectrum is due to the $\mathrm{CH}_{2}$ group of L-Arginine. The spectrum shows two peaks at $\delta=3.201 \mathrm{ppm}$ and $\delta=3.717 \mathrm{ppm}$ corresponds to the $\mathrm{CH}_{2}$ and $\mathrm{CH}$ groups of L-Arginine. The resonance peak observed at $\delta=6.285 \mathrm{ppm}$ exhibits the presence of $\mathrm{CH}_{2}$ methy- 


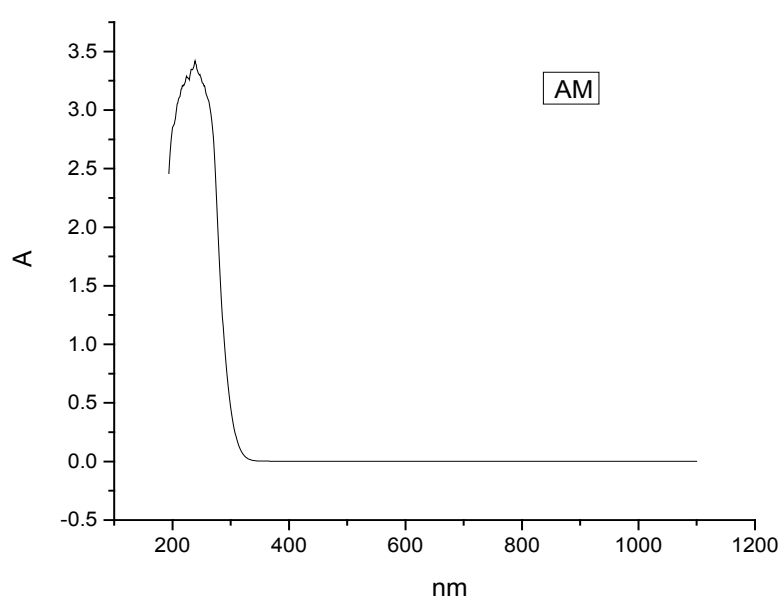

Figure 4. UV-VIS-NIR absorption Spectrum of L-Arginine maleate dihydrate crystal.

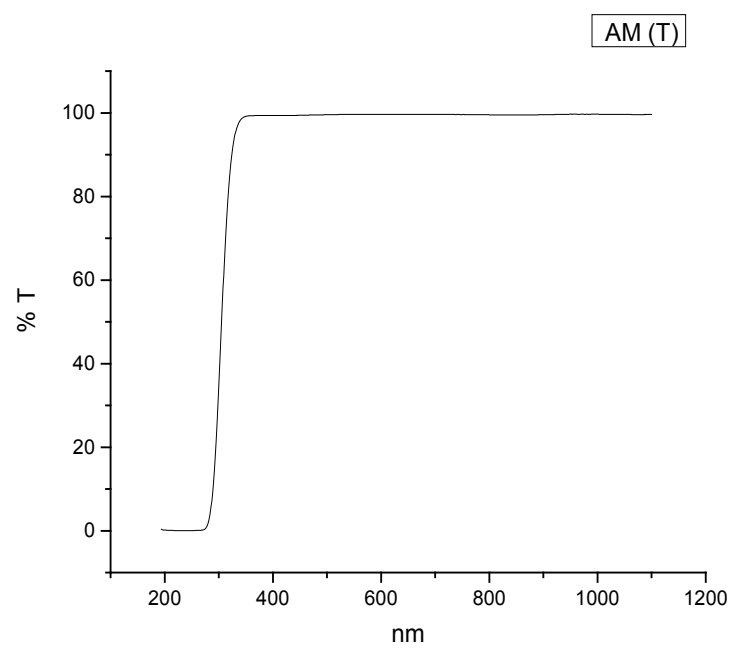

Figure 5. UV-VIS-NIR transmission Spectrum of L-Arginine maleate dihydrate crystal.

lene proton of maleic acid. The absence of peaks for $\mathrm{NH}_{2}$ and $\mathrm{COOH}$ group indicates that they are ionic in nature and are involved in secondary forces. It is interesting to note that the $\mathrm{CH}$ peak observed at $3.27 \mathrm{ppm}$ for L-Arginine is shifted to $3.717 \mathrm{ppm}$ for L-Arginine maleate dihydrate. This is due to the protonation of L-Arginine $\left(\mathrm{NH}_{3}^{+}\right)$by maleic acid $\left(\mathrm{COO}^{-}\right)$as shown below.

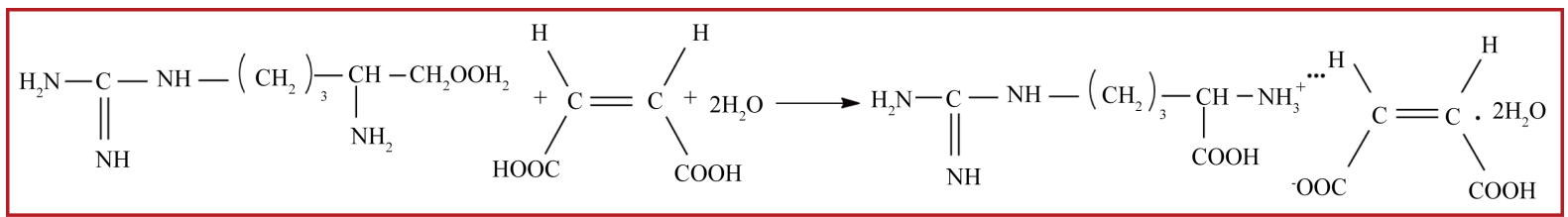

L-Arginine

Maleic acid

L-Arginine maleate dihydrate

The ${ }^{13} \mathrm{C}$-NMR spectrum of L-Arginine maleate dihydrate contains eight signals. The resonance peaks at $\delta=$ $174.27 \mathrm{ppm}$ and $\delta=170.81 \mathrm{ppm}$ is due to the carboxylic groups of L-Arginine and maleic acid. The resonance signal observed at $\delta=156.71 \mathrm{ppm}$ is due to the carbon attached to $\mathrm{HN}=\mathrm{C}-\mathrm{NH}_{2}$ group. The carbon attached to amino group shows its resonance peak at $\delta=54.24 \mathrm{ppm}$. The peaks at $\delta=40.45 \mathrm{ppm}, \delta=27.49 \mathrm{ppm}$ and $\delta=$ $23.84 \mathrm{ppm}$ are due to the carbon environments of $\mathrm{CH}_{2}$ groups of L-Arginine. The $\mathrm{CH}$ group of maleic acid gives 


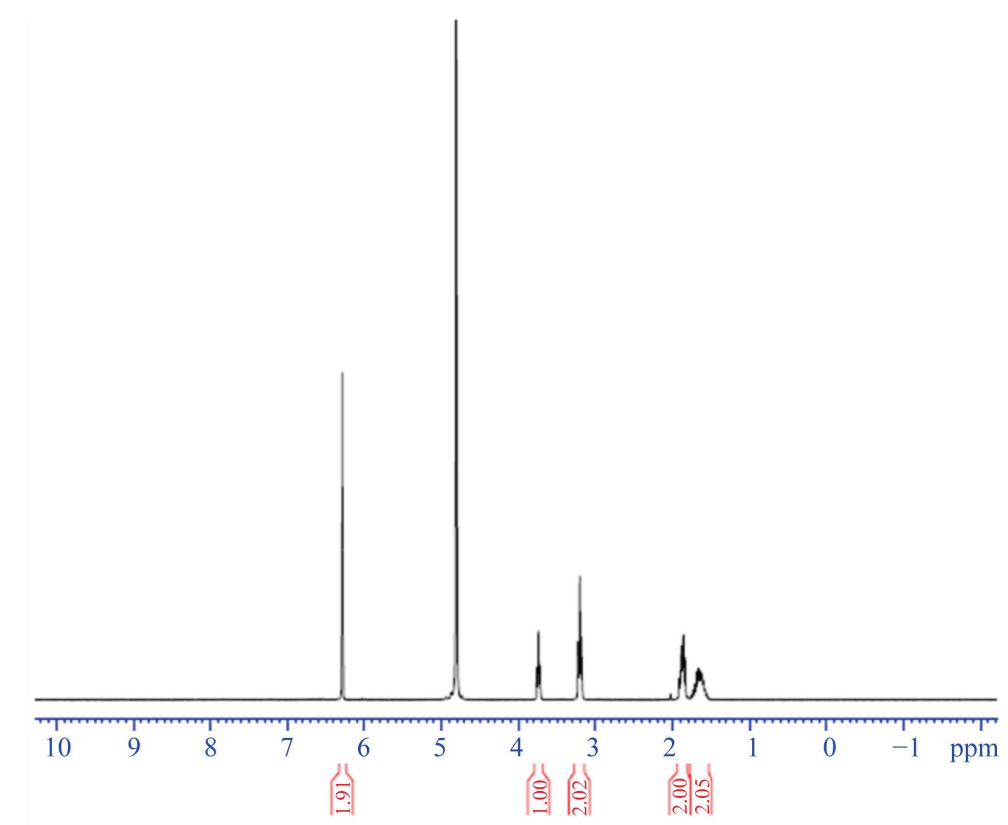

Figure 6. ${ }^{1} \mathrm{H}-\mathrm{NMR}$ Spectrum of L-Arginine maleate dihydrate crystal.
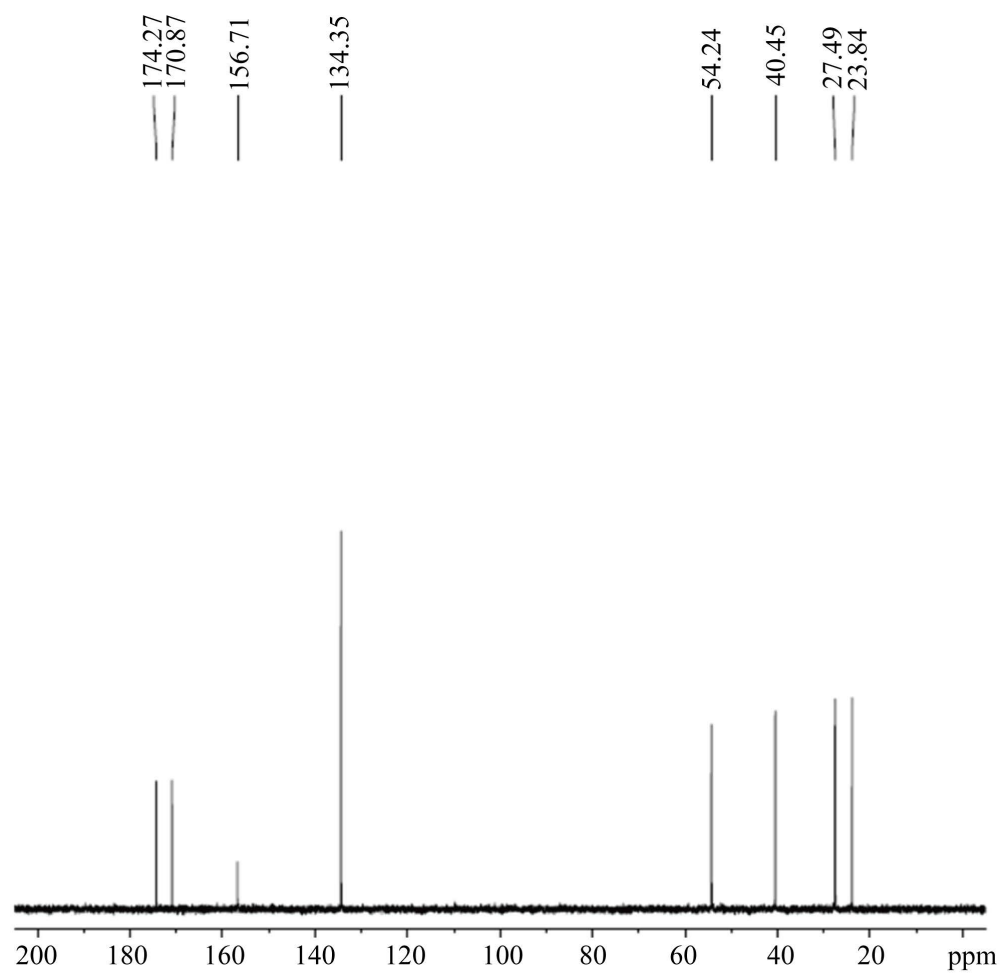

Figure $7 .{ }^{13} \mathrm{C}$-NMR Spectrum of L-Arginine maleate dihydrate crystal.

rise to a signal at $\delta=134.35 \mathrm{ppm}$.

\subsection{Thermal Analysis}

The thermo gravimetric analysis and differential thermal analysis spectra are obtained for L-Arginine maleate dihydrate crystal. The TGA/DTA curve is given in Figure 8. The initial mass of the materials used for the analy- 
Table 3. FTIR and FT Raman spectral assignments of L-Arginine maleate dihydrate crystal.

\begin{tabular}{cccc}
\hline & Wavenumber $\mathrm{cm}^{-1}$ & & Assignments \\
\hline 3400 & FT-Raman & - & OH stretching \\
3054 & 3043 & $\mathrm{NH}^{2}$ stretching vibration \\
2951 & 2925 & $\mathrm{CH}_{3}$ asymmetric stretching \\
1677 & 1680 & $\mathrm{NH}_{3}^{+}$asymmetric deformation \\
1627 & 1610 & $\mathrm{COO}^{-}$asymmetric stretching \\
1389 & 1392 & $\mathrm{COO}^{-}$symmetric stretching \\
1358 & 1339 & $\mathrm{C}^{-\mathrm{CH}^{2}}$ in plane deformation \\
1312 & 1314 & $\mathrm{CH}^{\text {bending }}$ \\
1166 & 1172 & $\mathrm{NH}_{3}^{+}$rocking \\
1111 & 1109 & $\mathrm{NH}_{3}^{+}$rocking \\
1021 & 1016 & $\mathrm{C}^{\mathrm{N}}$ stretching \\
868 & 851 & $\mathrm{COO}^{-}$rocking \\
796 & 801 & $\mathrm{CH}^{2}$ rocking \\
661 & 662 & $\mathrm{CH}_{2}$ rocking \\
573 & 545 & $\mathrm{COO}^{-}$wagging \\
\hline
\end{tabular}

Table 4. The chemical shifts in ${ }^{1} \mathrm{H}-\mathrm{NMR}$ spectrum of L-Arginine maleate dihydrate crystal.

\begin{tabular}{cccc}
\hline & \multicolumn{2}{c}{ Chemical shift $\delta(\mathrm{ppm})$} & \\
\hline L-Arginine maleate dihydrate & L-Arginine & Maleic acid & Group identification \\
\hline 6.285 & - & 6.285 & $-\mathrm{CH}-$ \\
3.717 & 3.27 & - & $-\mathrm{CH}-$ \\
3.201 & 3.21 & - & $-\mathrm{CH}_{2-}$ \\
1.889 & 1.63 & - & $-\mathrm{CH}_{2-}$ \\
1.629 & 1.63 & - & $-\mathrm{CH}_{2-}$ \\
\hline
\end{tabular}

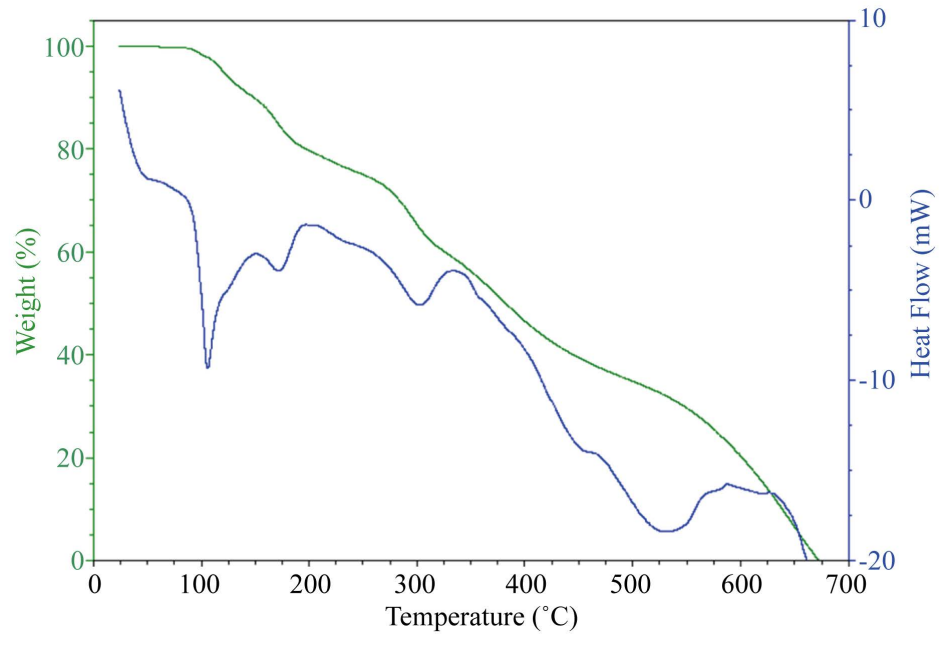

Figure 8. TGA/DTA curve of L-Arginine maleate dihydrate crystal. 
sis was $5.735 \mathrm{mg}$ and the final mass left out after the experiment was only $-0.1420 \%(-0.008142 \mathrm{mg})$ of initial mass. The material starts decomposing at $107^{\circ} \mathrm{C}$ with the loss of water of crystallization. The TGA curve also shows that the decomposition between the temperature ranges $178^{\circ} \mathrm{C}-301^{\circ} \mathrm{C}$ results in the liberation of carbondioxide in the compound. The endothermic peak at $178^{\circ} \mathrm{C}$ corresponds to the decomposition of maleic acid. The next stage of decomposition occurring between $301^{\circ} \mathrm{C}$ and $538^{\circ} \mathrm{C}$ is due to the removal of ammonia present in the compound. After this, the decomposition of L-Arginine maleate dihydrate continues upto $700^{\circ} \mathrm{C}$.

The DSC curve shown in Figure 9 reveals that the endothermic peak at $107^{\circ} \mathrm{C}$ is assigned to the decomposition of the material which is also evident in the DTA curve. Further, endothermic peaks were due to the volatilization of the compound observed during the decomposition stages which matches with the TG/DTA curves.

\subsection{Second Harmonic Generation Studies}

The powder second harmonic generation (SHG) test was carried out for L-Arginine maleate dihydrate crystal using Kurtz and Perry technique [15]. The powdered sample of the crystal was tightly packed in a capillary tube of $1.5 \mathrm{~mm}$ diameter and was illuminated by a high intense beam of laser radiation of wavelength $1064 \mathrm{~nm}$, with a pulse width of $10 \mathrm{~ns}$ and an input beam energy of $1.6 \mathrm{~mJ} /$ pulse. The material exhibits nonlinear optical property thus by the emission of $532 \mathrm{~nm}$ wavelength of green radiation. The second harmonic generation efficiency was found to be 1.4 times that of KDP.

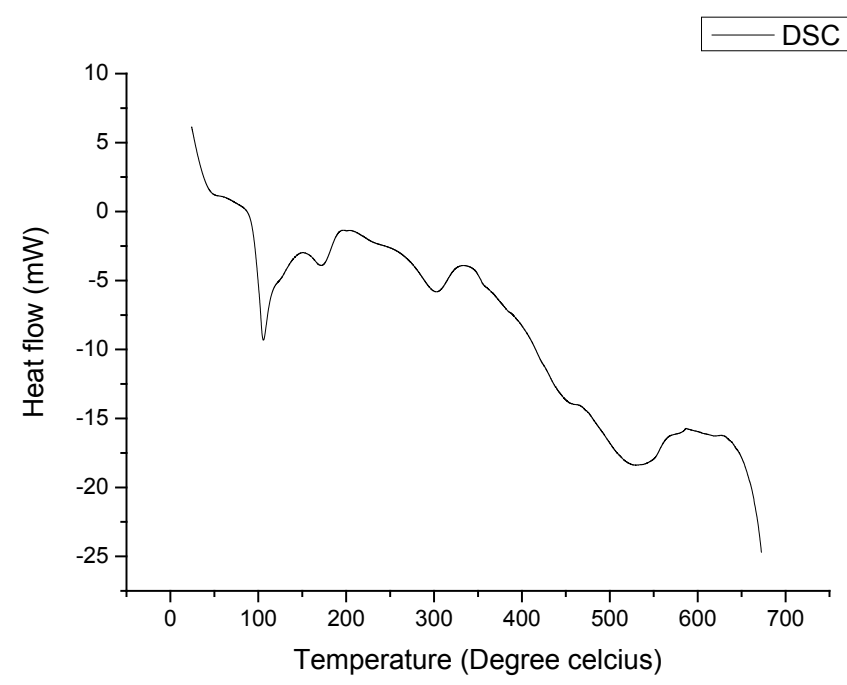

Figure 9. DSC curve of L-Arginine maleate dihydrate crystal.

Table 5. The chemical shifts in ${ }^{13} \mathrm{C}$-NMR spectrum of L-Arginine maleate dihydrate crystal.

\begin{tabular}{cccc}
\hline & \multicolumn{2}{c}{ Chemical shift $\delta(\mathrm{ppm})$} & \\
\hline L-Arginine maleate dihydrate & L-Arginine & Maleic acid & Group identification \\
\hline 174.27 & 175.38 & - & $-\mathrm{COOH}-$ \\
170.81 & - & 166.53 & $-\mathrm{COOH}-$ \\
156.71 & 157.85 & - & $-\mathrm{NH}=\mathrm{C}-\mathrm{NH}_{2-}$ \\
134.35 & - & 129.99 & $-\mathrm{CH}_{-}$ \\
54.24 & 55.45 & - & $-\mathrm{CH}_{-}-\mathrm{NH}_{2-}$ \\
40.45 & 41.64 & - & $-\mathrm{CH}_{2-}$ \\
27.49 & 28.77 & - & $-\mathrm{CH}_{2-}$ \\
23.84 & 25.03 & - & $-\mathrm{CH}_{2-}$ \\
\hline
\end{tabular}




\section{Conclusion}

L-Arginine maleate dihydrate crystal was grown by liquid diffusion technique at room temperature. Single crystal XRD studies reveal that the crystal L-Arginine maleate dihydrate belongs to triclinic structure and noncentrosymmetric space group. The functional groups of the crystal were identified by FT-IR and FT Raman spectroscopy. The optical absorption spectrum reveals that the crystal is transparent in the entire UV-VIS-NIR region with the lower cut-off wavelength of $238 \mathrm{~nm} .{ }^{1} \mathrm{H}-\mathrm{NMR}$ and ${ }^{13} \mathrm{C}-\mathrm{NMR}$ spectral analyses determine the structure of the grown crystal. From the thermal studies, the thermal stability was analyzed. Kurtz and Perry powder technique confirms that L-Arginine maleate dihydrate exhibits the nonlinear optical property.

\section{Acknowledgements}

The authors wish to thank SASTRA University for the Powder XRD, NMR and TG/DTA and DSC characterization facilities. The authors thank St. Joseph College, Tiruchirappalli for FTIR and UV spectra and IIT, Chennai for single crystal XRD and FT-Raman studies. The authors are also grateful to Dr. P. K. Das, Indian Institute of Science, Bangalore for the measurement of SHG efficiency.

\section{References}

[1] Rajarajan, K., Joseph, G.P., Ravikumar, M., Kumar, S.M., Potheher, I.V., Pragasam, A.J.A. and Sagayaraj, P. (2007) Growth and Optical Studies of a Novel Organometallic Complex NLO Crystal: Tetrathiourea Cadmiun (II) Tetrathiocyanato Zinc (II). Materials and Manufacturing Processes, 22, 370-374. http://dx.doi.org/10.1080/10426910701190857

[2] Caroline, M.L. and Vasudevan, S. (2008) Growth and Characterization of an Organic Material L-Alanine Alaninium Nitrate. Materials Letters, 62, 2245-2248. http://dx.doi.org/10.1016/j.matlet.2007.11.059

[3] Pan, F., Bosshard, C., Wong, M.S., Serbutoviezt, C., Follonier, S., Günter, P. and Schenk, K. (1996) Polymorphism, Growth and Characterization of a New Organic Nonlinear Optical Crystal: 4-Dimethylaminobenzaldehyde-4-Nitrophenylhydrazone (DANPH). Journal of Crystal Growth, 165, 273-283. http://dx.doi.org/10.1016/0022-0248(96)00179-0

[4] Yokoo, A., Tamaru, S., Yokohama, L., Ito, H. and Kaino, T. (1995) A New Growth Method for Long Rod-Like Organic Nonlinear Optical Crystals with Phase-Matched Direction. Journal of Crystal Growth, 156, 279-284. http://dx.doi.org/10.1016/0022-0248(95)00260-X

[5] Natarajan, S., Britto, S.A.M. and Ramachandran, E. (2006) Growth, Thermal, Spectroscopic, and Optical Studies of L-Alaninium Maleate: A New Organic Nonlinear Optical Material. Crystal Growth and Design, 6, 137-140. http://dx.doi.org/10.1021/cg0502439

[6] Vasantha, K. and Dhanuskodi, S. (2004) Single Crystal Growth and Characterization of Phase-Matchable L-Arginine Maleate: A Potential Nonlinear Optical Material. Journal of Crystal Growth, 269, 333-341. http://dx.doi.org/10.1016/j.jcrysgro.2004.04.113

[7] Mallik, T., Kar, T., Bocelli, G. and Musatti, A. (2005) Synthesis, Crystal Structure and Solubility of $\mathrm{C}_{6} \mathrm{H}_{14} \mathrm{~N}_{4} \mathrm{O}_{2}$, $\mathrm{C}_{4} \mathrm{H}_{4} \mathrm{O}_{4}, 2 \mathrm{H}_{2} \mathrm{O}$. Science and Technology of Advanced Materials, 6, 508-512. http://dx.doi.org/10.1016/j.stam.2005.01.001

[8] Kalaiselvi, D., Kumar, M.R. and Jayavel, R. (2008) Growth and Characterization of Nonlinear Optical L-Arginine Maleate Dehydrate Single Crystals. Materials Letters, 62, 755-758. http://dx.doi.org/10.1016/j.matlet.2007.06.054

[9] Baraniraj, T. and Philominathan, P. (2010) Growth and Characterization of NLO Based L-Arginine Maleate Dehydrate Single Crystal. Spectrochimica Acta A, 75, 74-76. http://dx.doi.org/10.1016/j.saa.2009.09.043

[10] Karunanithi, U., Arulmozhi, S. and Madhavan, J. (2012) Synthesis and Characterization of Pure and Doped L-Arginine Maleate Single Crystals. IOSR Journal of Applied Physics, 1, 14-18. http://dx.doi.org/10.9790/4861-0121418

[11] Mallik, T. and Kar, T. (2005) Synthesis, Growth and Characterization of a New Nonlinear Optical Crystal: L-Arginine Maleate Dehydrate. Crystal Research and Technology, 40, 778-781. http://dx.doi.org/10.1002/crat.200410430

[12] Sun, Z.H., Yu, W.T., Cheng, X.F., Wang, X.Q., Zhang, G.H., Yu, G., Fan, H.L. and Xu, D. (2008) MSynthesis, Crystal Structure and Vibrational Spectroscopy of a Nonlinear Optical Crystal: L-Arginine Maleate Dehydrate. Optical Materials, 30, 1001-1006. http://dx.doi.org/10.1016/j.optmat.2007.05.028

[13] Umadevi, T., Lawrence, N., Ramesh, B.R. and Ramamurthy, K. (2008) Growth and Characterization of L-Prolinium Picrate Single Crystal: A Promising NLO Crystal. Journal of Crystal Growth, 310, 116-123. http://dx.doi.org/10.1016/j.jcrysgro.2007.10.011 
[14] Rodrigues Jr., J.J., Misoguti, L., Nunes, F.D., Mendonça, C.R. and Zilio, S.C. (2003) Optical Properties of L-Threonine Crystals. Optical Materials, 22, 235-240. http://dx.doi.org/10.1016/S0925-3467(02)00270-7

[15] Kurtz, S.K. and Perry, T.T. (1968) A Powder Technique for the Evaluation of Nonlinear Optical Materials. Journal of Applied Physics, 39, 3798-3813. http://dx.doi.org/10.1063/1.1656857 